\title{
Asthmagenic properties of a newly developed detergent ingredient: sodium iso-nonanoyl oxybenzene sulphonate
}

\author{
S C Stenton, J H Dennis, E H Walters, D J Hendrick
}

\begin{abstract}
The suspicion that a newly developed detergent ingredient, sodium iso-nonanoyl oxybenzene sulphonate (SINOS), was inducing asthma among a workforce led to a series of inhalation challenge tests to determine the specificity and dose response characteristics of its asthma provoking properties. Three previously exposed workers, three non-exposed nonasthmatic controls, and three non-exposed asthmatic controls were challenged with SINOS $0.01-100 \mu \mathrm{g}$ and another chemically similar surface active detergent ingredient, linear alkyl benzene sulphonate (LAS) 0.01$100 \mu \mathrm{g}$. Asthmatic symptoms, late falls in $\mathrm{FEV}_{1}$, and increases in non-specific bronchial responsiveness were seen after the inhalation of SINOS in all three workers, confirming SINOS as a cause of occupational asthma. No changes were seen after the inhalation of SINOS in either group of control subjects nor after LAS in any subject. These findings suggest that SINOS causes asthma through a specific hypersensitivity mechanism unrelated to its surface active properties.
\end{abstract}

During the industrial development of a new detergent ingredient (sodium iso-nonanoyl oxybenzene sulphonate, SINOS, (fig 1)), which has bleach activating and surface active properties, rashes, rhinitis, conjunctivitis, and wheezing developed in several workers over 12-18 months. In one worker with respiratory symptoms late asthmatic reactions and increases in non-specific bronchial responsiveness (NSBR) were noted both on returning to the workplace after a two week absence and after a series of inhalation challenge tests in the laboratory. ${ }^{1}$

Chest Unit, Newcastle General Hospital, University of Newcastle upon Tyne, Newcastle upon Tyne NE4 6BE

S C Stenton, J H Dennis, E H Walters, D J Hendrick
Occupational asthma attributable to SINOS was consequently diagnosed.

The challenge tests entailed the daily inhalation of nebulised SINOS with increasing doses. Whereas clear cut late asthmatic reactions (LARs) were seen after two separate challenges with the highest SINOS dose $(32 \mu \mathrm{g})$, there were also late falls in ventilatory function of smaller magnitude after lower doses. An apparently linear dose response relation relating the magnitude of the late declines in ventilatory function to the logarithm of the challenge dose was observed. ${ }^{1}$ Such a dose response relation for LARs after inhalation challenge with common allergens or industrial agents had not previously been published and it raised the question whether SINOS might be acting through an unusual mechanism.

The present study has investigated the specificity of SINOS in causing occupational asthma using a further series of inhalation challenge studies involving (1) the index case and two other workers with symptoms suggesting occupational asthma, (2) three unexposed non-asthmatic control subjects, and (3) three unexposed control subjects with symptomatic asthma. To determine whether any asthmagenic properties could be related to the surface active properties of SINOS-that is, its ability to reduce surface tension-each subject also underwent a series of inhalation challenges with the structurally similar detergent ingredient linear alkyl benzene sulphonate
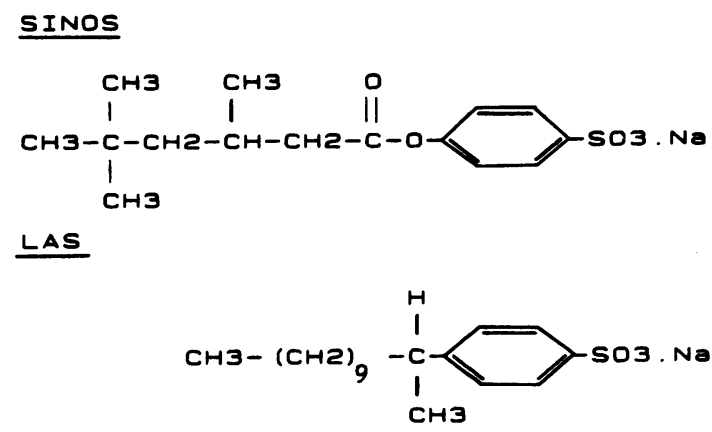

Figure 1 SINOS: sodium iso-nonanoyl oxybenzene sulphonate and LAS: linear alkyl benzene sulphonate. 
(LAS, fig 1). ${ }^{2}$ LAS has been widely used throughout the detergent industry for many years without any suspicion of it causing occupational asthma. ${ }^{3}$ It is chemically similar to SINOS and shares its surface active but not its bleach activating properties.

\begin{abstract}
Methods
SUBJECTS

Three development technicians who had been occupationally exposed to SINOS within a research and development plant and had symptoms suggesting occupational asthma were studied along with three non-asthmatic control subjects selected from the investigating team and three asthmatic subjects from our clinic population. None of the six control subjects had had previous exposure to SINOS. The asthmatic control subjects were chosen to have similar levels of NSBR to those measured in the workers at the time of their symptoms. The nonasthmatic controls all had low levels of NSBR which could not be quantified using our standard methacholine challenge technique ${ }^{4}$ - that is, they did not show a $20^{\circ}{ }^{\circ}$ fall in $\mathrm{FEV}_{1}$ after the maximum cumulative dose of $6.4 \mathrm{mg}$. The mean age of the workers was 36 , of the non-asthmatic controls 38 , and of the asthmatic controls 26 . Two workers and two control subjects were atopic (at least one skin prick test to common allergens giving a weal diameter greater than that of a $0 \cdot 1 \%$, solution of histamine). All nine subjects had pre-study $\mathrm{FEV}_{1}$ at least $70 \%$ of the predicted value and all subjects gave fully informed consent. The study was approved by the local ethics committee.
\end{abstract}

\section{CHALLENGE PROTOCOL}

Each subject underwent one series of daily inhalation challenge tests with SINOS and one series with LAS, the sequence being chosen randomly. For each agent the starting dose was $0.01 \mu \mathrm{g}$. Doses were increased daily by $3 \cdot 2$-fold $(\sqrt{10})$ increments until a reaction causing characteristic symptoms and a $20 \%$ fall in $\mathrm{FEV}_{1}$ occurred or the maximum dose of $100 \mu \mathrm{g}$ was administered. At least three saline control challenges were interspersed within each challenge series, all challenges being administered double blind with respect to the subject and the immediately supervising physician. The dose range for SINOS $(0.01-100 \mu \mathrm{g})$ was based on environmental measurements in the manufacturing plant. In the weeks immediately before the initial investigation, maximum exposures of the order $0.02-1.00 \mu \mathrm{g} /$ hour $(0 \cdot 1-10 \mu \mathrm{g} /$ day $)$ had been tolerated without undue discomfort. A starting does of $0.01 \mu \mathrm{g}$ was consequently considered to be both safe and suitable. Earlier exposures were thought to have been higher and a failure to respond to $100 \mu \mathrm{g}$ was considered improbable if SINOS hypersensitivity truly existed.
The dose range for LAS was chosen to match that for $\stackrel{?}{?}$ SINOS. Although occupational exposure to both $\vec{F}$ agents had been as a dry powder of respirable size, each was prepared as a solution for inhalation tests to allow greater precision of dose.

PREPARATION OF SOLUTIONS AND CHALLENGES Stock solutions of SINOS and LAS $2 \mathrm{mg} / \mathrm{ml}$ in $0.4 \%$ phenol saline were prepared weekly and appropriate serial dilutions made using the phenol saline solu- $\vec{\circ}$ tion. Diluted samples were then labelled and stored at $4^{\circ} \mathrm{C}$. The challenge sequence (LAS series first or SINOS series first) having been chosen in advance, a decision was made each day by one of us whether to $\exists$ use the next dose of SINOS/LAS or a saline control, and the appropriate solution was placed in an unlabelled container.

Nebulised challenges were performed using an or inhalation dosimeter; a total of $50 \mu \mathrm{l}$ of challenge 을 solution being administered from five inhalations. The dosimeter was calibrated each morning and $\subseteq$ delivered $10 \mu \mathrm{l} \pm 5 \%$ to the mouth with each $\vec{\nabla}$ inhalation. The phenol effectively disguised any $\overrightarrow{0}$ smell/taste of the detergent and the body of the $\varnothing$ nebuliser was covered to mask any frothing provoked by the higher doses of detergent. Thus neither the subject nor the immediately supervising physician was aware of the identity of the challenge agent, its possible dose, or whether a control challenge was being administered.

MONITORING TESTS

NSBR was measured as $\mathrm{PD}_{20} \mathrm{FEV}_{1}$ to methacholine using a dosimeter technique during the week before and at intervals after each challenge series (see table 1). ${ }^{4}$ Measurements were made on different days at 1000.

On each challenge day, ventilatory function was monitored as $\mathrm{FEV}_{1}$ (mean of three technically satisfactory measurements). It was measured at 10 minute intervals from 0920 to 1000 using a dry wedge bellows spirometer (Vitalograph, Buckingham). Inhalation challenge was at 1000 , after which FEV was measured at 10 minute intervals until 1120 to detect any early asthmatic reaction. It was then $N$ measured hourly to 2200 , at 0300 if there had been any symptoms during the day, and from 0800 to $1000 \mathrm{~N}$ the next day to complete a 24 hour period of $\omega$ surveillance. All respiratory symptoms over the 24 श hour monitoring period were recorded.

SUPERVISION

Before the challenge protocol, subjects measured $\mathrm{FEV}_{1}$ as above on three days. For each hour, the lowest $\mathrm{FEV}_{1}$ recorded over these three days was

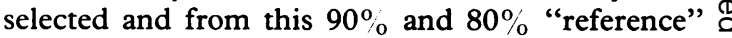
values were calculated. After each inhalation challenge, subjects were observed in the laboratory 8 until 1200 when the possibility of an immediate 
Table 1 Changes in bronchial responsiveness in the workers and asthmatic controls

\begin{tabular}{|c|c|c|c|}
\hline \multirow{2}{*}{$\begin{array}{l}\text { Challenge test } \\
\text { Sequence }\end{array}$} & \multicolumn{3}{|c|}{$P D_{20} F E V_{1}(\mu g$ methacholine) } \\
\hline & $\begin{array}{l}\text { Asthmatic } \\
\text { control } 1\end{array}$ & Worker 1 & Worker 3 \\
\hline $\begin{array}{l}\text { Before challenge: } \\
\quad 1 \\
2 \\
\text { After LAS: }\end{array}$ & $\begin{array}{l}130 \\
260\end{array}$ & $\begin{array}{r}800 \\
1300\end{array}$ & $\begin{array}{l}230 \\
250\end{array}$ \\
\hline $\begin{array}{l}3 \\
4 \\
\text { After SINOS: }\end{array}$ & $\begin{array}{l}420 \\
580\end{array}$ & 950 & $\begin{array}{r}6400 \\
>6400\end{array}$ \\
\hline $\begin{array}{r}5 \\
6 \\
7 \\
8 \\
9 \\
10\end{array}$ & 700 & $\begin{array}{c}185 \text { (day } 1) \\
200(\text { day } 3) \\
270(\text { day } 6) \\
400(\text { day } 10) \\
500(\text { day } 13) \\
2000(\text { day } 29)\end{array}$ & $\begin{array}{c}110(\text { day } 1) \\
440(\text { day } 2) \\
320(\text { day } 3) \\
460(\text { day } 8) \\
1250(\text { day } 11) \\
3800(\text { day } 45)\end{array}$ \\
\hline Sequence & $\begin{array}{l}\text { Asthmatic } \\
\text { control } 2\end{array}$ & $\begin{array}{l}\text { Asthmatic } \\
\text { control } 3\end{array}$ & Worker $2^{\star}$ \\
\hline $\begin{array}{c}\text { Before challenge: } \\
1 \\
2 \\
3\end{array}$ & $\begin{array}{l}400 \\
600\end{array}$ & $\begin{array}{l}320 \\
152 \\
400\end{array}$ & $\begin{array}{l}0 \% \\
5 \%\end{array}$ \\
\hline $\begin{array}{l}\text { After SINOS: } \\
\quad 4 \\
5 \\
6 \\
\text { After LAS: }\end{array}$ & $\begin{array}{l}530 \\
540\end{array}$ & 145 & $\begin{array}{l}13 \% \text { (day } 1 \\
15^{\circ} \%(\text { day } 12) \\
12 \% \text { (day } 14)\end{array}$ \\
\hline 7 & 380 & 340 & $6^{\circ}$ o \\
\hline
\end{tabular}

*Bronchial responsiveness for worker 2 expressed as $\%$ fall of FEV , after $6.4 \mathrm{mg}$ methacholine.

A decreasing $\mathrm{PD}_{20}$ indicates an increasing level of bronchial responsiveness.

Three subjects were challenged with LAS first and three with SINOS first. Each challenge series followed immediately from the previous: thus for workers 1 and 3, the post-LAS measurements of bronchial responsiveness are the pre-SINOS measurements.

No non-asthmatic control subject showed a measurable $\mathbf{P D}_{20}$ at any stage.

Day 0 is the day of the last challenge in the series.

asthmatic reaction had passed. They then returned home with a spirometer to record $\mathrm{FEV}_{\text {, values }}$ without immediate supervision. They were instructed to contact the supervising doctor if $\mathrm{FEV}_{1}$ measurements fell below the $90 \%$ reference value. If the $\mathrm{FEV}_{1}$ fell below the $80 \%$ reference value the immediately supervising physician was required to meet the subject, confirm the accuracy of the measurements, and arrange further supervision or treatment as necessary.

\section{EXPRESSION OF RESULTS}

Late declines in ventilatory function were expressed cumulatively by the $2-12$ hour "area decrement" from the $\mathrm{FEV}_{1} /$ time plot. This comprised the area in litre $\times$ hours between a line extrapolated from the mean baseline for the day and the hourly measurements of $\mathrm{FEV}_{1}$ between two and 12 hours after challenge. It takes into account all measurements during the observation period and is subject to less variation than a single measurement of ventilatory function-for example, the lowest $\mathrm{FEV}_{1}$ after challenge or the maximum fall in $\mathrm{FEV}_{1}$ from baseline.

\section{SUBTILISIN CHALLENGE}

For worker 1, a series of similar inhalation challenge tests was performed using the detergent enzyme, subtilisin, to which he had also been exposed occupationally. Challenges over the dose range $0.001-0.1 \mu \mathrm{g}$ were performed with saline controls interspersed in a double blind manner as described above.

\section{Results}

Challenge with SINOS produced unequivocal LARs with symptoms of wheeze/breathlessness and late declines in $\mathrm{FEV}_{1}$ at the highest challenge doses in all three workers (table 2, fig 2). With workers 1 and 3 there were significant increases in NSBR that persisted for up to six weeks (table 1); a doubling or halving of the $\mathrm{PD}_{20}$ suggesting a significant change. ${ }^{4} \mathrm{With}$ worker 2, a $\mathrm{PD}_{20} \mathrm{FEV}_{1}$ was never obtained. A $\mathrm{PD}_{10} \mathrm{FEV}_{1}$ was briefly obtainable immediately after the SINOS challenge series suggesting that there had been an increase in NSBR if not into the conventionally measured range. Dose response analyses suggested log linear relation between the challenge dose of SINOS and the magnitude of the LAR for two workers, though for the third (worker 2), such a relation was not obvious (fig 3 ).

No symptoms, falls in $\mathrm{FEV}_{1}$, or increases in NSBR were seen after challenge with SINOS in the three non-asthmatic control subjects or in the three asthmatic controls. FEV 1 area decrements after the maximum SINOS doses in all six control subjects did not exceed those seen on control days (table 2). Table 1 shows $\mathrm{PD}_{20} \mathrm{FEV}_{1}$ values for the three asthmatic control subjects. Subject 1 showed a steady im-

Table 2 Changes in ventilatory function following challenge with SINOS and LAS

\begin{tabular}{lccc}
\hline \multicolumn{4}{c}{ 2-12 Hour FEV, area decrement $(l \times h)$} \\
\cline { 2 - 4 } $\begin{array}{l}\text { Test } \\
\text { subject }\end{array}$ & $\begin{array}{c}\text { Control days } \\
\text { (median } \mathcal{E} \text { range) }\end{array}$ & $\begin{array}{c}\text { SINOS } \\
(100 \mu g)\end{array}$ & $\begin{array}{l}L A S \\
(100 \mu g)\end{array}$ \\
\hline Workers: & & \\
1 & $0.69(-0.96 ; 1.22)$ & $7.47 \star$ & 0.50 \\
2 & $-0.17(-1.50 ; 0.53)$ & 2.64 & 0.98 \\
3 & $-0.11(-2.58 ; 1.23)$ & 7.62 & 0.10 \\
Non-asthmatic controls: & & \\
1 & $0.31(-1.11 ; 1.39)$ & 0.26 & -0.28 \\
2 & $0.55(-0.16 ; 1.40)$ & 0.71 & -0.06 \\
3 & $0.22(-0.02 ; 1.41)$ & -1.63 & -0.68 \\
Asthmatic controls: & & & \\
1 & $-0.02(-1.66 ; 1.24)$ & 0.04 & -0.59 \\
2 & $-0.95(-2.17 ; 2.19)$ & -0.47 & -2.03 \\
3 & $0.47(-0.46 ; 2.30)$ & 0.42 & 1.24 \\
\hline
\end{tabular}

^ Maximum dose of SINOS $=32 \mu \mathrm{g}$

1 All 2-12 hour FEV area decrements after challenge with SINOS $100 \mu \mathrm{g}$ or LAS $100 \mu \mathrm{g}$ in the control subjects were within the range observed on control days.

2 Similar results were noted with the 2-24 hour FEV, area decrements.

3 A negative area decrement implies a net improvement in FEV, compared with baseline values. 

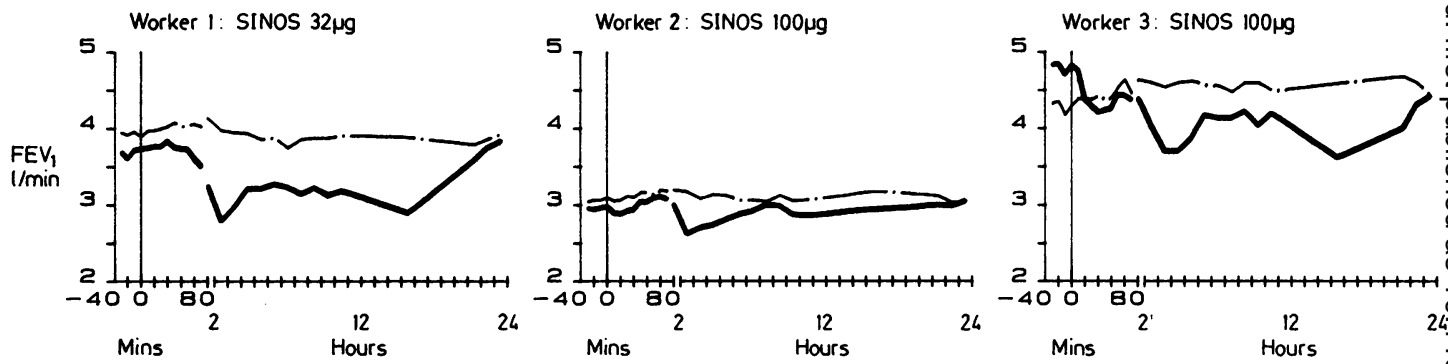

Figure 2 Late asthmatic reactions after challenge with SINOS in three workers.

challenges with highest challenge doses of SINOS for each worker, ___ a control challenge with saline. All challenges were administered at 1000.

provement in NSBR (increase in $\mathrm{PD}_{20} \mathrm{FEV}_{1}$ ) throughout the challenge series, possibly due to his removal from domestic environmental agents during the study period; and the other asthmatic controls showed no significant changes. None of the nonasthmatic controls showed $\mathrm{PD}_{20} \mathrm{FEV}_{1}$ at any stage of the study.

No symptoms, sustained falls in $\mathrm{FEV}_{1}$, or increases in NSBR were seen after LAS challenge in any
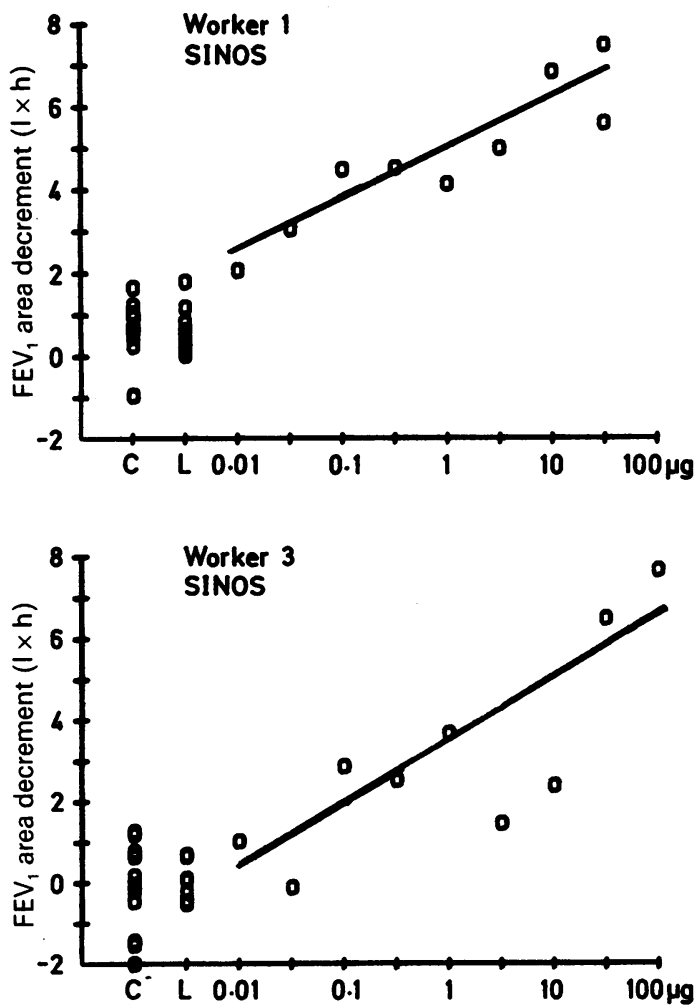

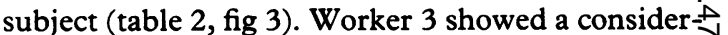
able increase in $\mathrm{PD}_{20} \mathrm{FEV}_{1}$ after challenge with LAS This may have been due to his removal from the workplace and consequent reduced exposure tơ SINOS during the LAS challenge series. Worker 2 showed an increase in 2-12 hour area decrement after LAS $100 \mu \mathrm{g}$ which just exceeded those on the controE days (table 1). This value, however, was not beyondo the $95^{\circ}$, confidence limit established for these area
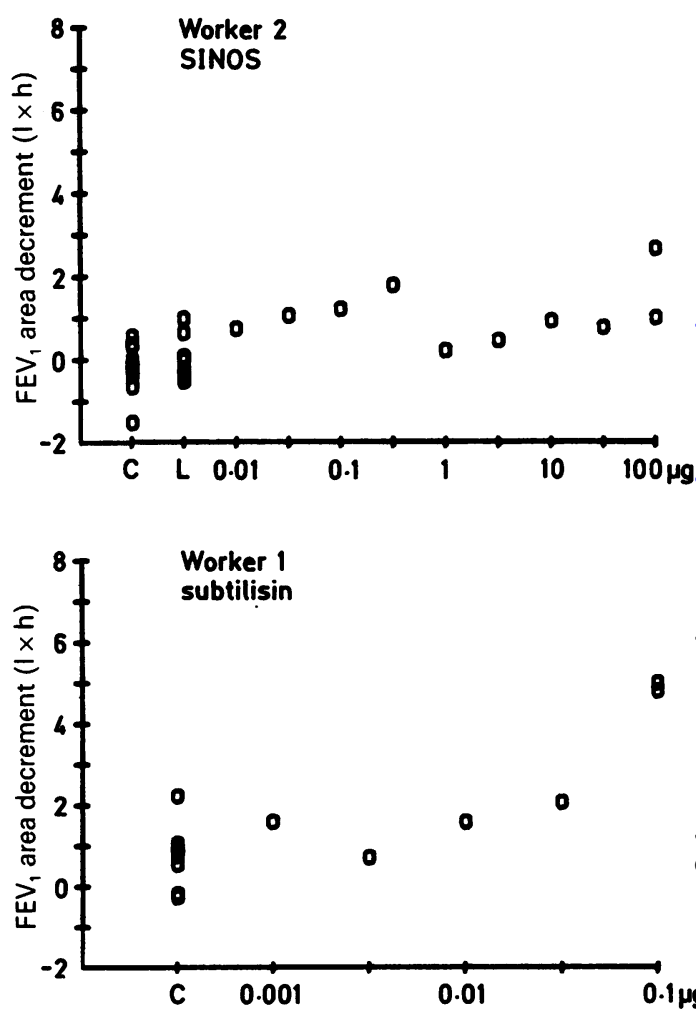

Figure 3 Dose response relations for late asthmatic responses to SINOS in three workers and subtilisin in one worker. $C=$ Control; FEV , monitoring without any challenge or after a saline control challenge; $L=$ challenges with $L A S O \cdot 01-$ $100 \mu \mathrm{g}$. Linear regression lines are plotted for workers 1 and 3. Regression equations are area decrement $=2.85+0.6 \times$ dose increment for worker 1 and area decrement $=-0.6+0.7 \times$ dose increment for worker 3 . Highest control measurement associated with subtilisin challenges occurred during challenge sequence after subtilisin $0.32 \mu \mathrm{g}$ and was probably influenced by reaction on preceding dm. 
decrements on control days, did not have a pattern typical of an LAR, and was not accompanied by symptoms or changes in NSBR.

Figure 3 shows the results of the subtilisin challenges in worker 1 . The threshold for LARs appeared to occur at about $0.01 \mu \mathrm{g}$. There was only a small increase in the magnitude of the reaction at $0.032 \mu \mathrm{g}$, followed by a more rapid increase in the response with symptoms and a maximum fall in $\mathrm{FEV}_{1}$ of $24 \%$ after the $0 \cdot 1 \mu \mathrm{g}$ challenge. This latter response was reproduced on retesting.

\section{Discussion}

Unequivocal symptoms, LARs, and increases in NSBR occurred after the SINOS challenge tests in the three workers confirming the role of SINOS as a potential inducer of occupational asthma. These results coupled with the lack of symptoms for several months after exposure first occurred, are typical features of occupational asthma. The apparent log linear dose response relation for the LARs was, however, unexpected when the index case was first studied in $1985 .{ }^{1}$ Such a relation had not then been reported for occupational or natural inducers of asthma and the question that arose was whether this relation indicated an unusual pathogenetic mechanism or whether with the refinements of our investigatory protocol we had simply clarified the normal pattern of reactivity at dose levels preceding the threshold of the clinically unequivocal reaction.

The original finding in worker 1 was reproduced in this study but the slope of the dose response relation had diminished slightly from 0.8 to $0.61 \times \mathrm{h}$ /dose increment over the intervening year spent without further exposure to SINOS. The data still suggested, however, that whereas moderate and clinically obvious LARs occurred after $32 \mu \mathrm{g}$ SINOS, LARs of smaller magnitude were occurring from the $0.032 \mu \mathrm{g}$ dose onwards. The size of the LAR, measured as the 2-12 hour area decrement, increased only fourfold whereas the dose of SINOS increased 3200-fold from 0.01 to $32 \mu \mathrm{g}$-seemingly in a log linear fashion.

The results obtained using the same protocol in workers 2 and 3 showed a similar picture. With worker 3 , the slope of the regression equation was somewhat greater than that of worker 1 , and the points on the dose response plot were less closely deployed about the regression line. The findings were, nevertheless, similar to those of worker 1 . With worker 2, the principal symptoms had been of rhinitis and conjunctivitis and the clinical evidence for asthma before this study was less convincing than for workers 1 and 3 . The dose response relation was less clearly log linear and its slope was flatter. There was a curious step in the dose response graph from 0.32 to $1 \mu \mathrm{g}$ but we could not find any artefact to account for it. There was a suspicion of a LAR after $0.32 \mu \mathrm{g}$ SINOS but it was not until the $100 \mu \mathrm{g}$ dose that there was a clinically unequivocal and symptomatic LAR. This analytical approach provides the framework for a statistical input to the recognition of LARs. A full description of the use of statistics in analysing asthmatic reactions is beyond the scope of this paper but is being published in detail elsewhere. ${ }^{5}$

It was of interest to examine the response to a more commonly recognised inducer of occupational asthma-subtilisin. ${ }^{6}$ Worker 1 had previously worked with this well recognised asthma inducer and had developed positive immediate skin prick test reactivity to it. The more rapid increase in response seen with increases in subtilisin dose is perhaps the pattern which is more widely expected. None the less increasing LARs over a tenfold dose range were shown and we cannot be confident that this pattern differs from that seen with SINOS, or that the SINOS pattern is unique.

In fact a similar dose response relation has also been shown for tetrachlorophthalic anhydride. ${ }^{?}$ It consequently appears that dose response relations for LARs may be elicited for a wider variety of occupational agents and possibly common allergens ${ }^{8}$ if study protocols are sufficiently robust. It should also be possible to elicit threshold values at which reactions first occur, though such "postsensitisation" values are not probably of much use in establishing conventional threshold limit values (or other statutory exposure limits) designed to prevent sensitisation occurring initially.

The closeness of fit of the dose response plots to the regression line is interesting. With all three workers there were examples of a dose increment producing a lesser area decrement. Part of this may be attributed to biological and measurement variability but part is likely to result from the daily challenge protocol. In general, challenges were not carried out at weekends and this would have allowed changes in NSBR induced by each SINOS challenge to subside partially or even fully before the next SINOS dose was administered. Similarly, a SINOS challenge after a saline control challenge was likely to produce a lesser reaction than one immediately after another SINOS challenge.

In two workers considerable changes in $\mathrm{PD}_{20} \mathrm{FEV}_{1}$ to methacholine were noted in association with the SINOS challenges. These persisted for up to six weeks. In the third worker a $\mathrm{PD}_{20} \mathrm{FEV}_{1}$ was never obtained. The development of a $\mathrm{PD}_{10} \mathrm{FEV}_{1}$ after the SINOS series does suggest, however, that an increase in NSBR occurred. The provocation of late asthmatic reactions in the absence of pre-existing NSBR measurable by $\mathrm{PD}_{20} \mathrm{FEV}_{1}$ has been reported but is an exception rather than the rule. ${ }^{9}$ It is consistent with the belief that the strength of asthmatic reactions to specific environmental agents 
(whether occupational or natural) is dependent on the dose, the degree of specific hypersensitivity, and the level of NSBR. In the presence of low levels of NSBR (below those measurable as $\mathrm{PD}_{20} \mathrm{FEV}_{1}$ to methacholine) late asthmatic reactions may still be observed if the challenge dose and the degree of specific hypersensitivity are sufficiently high.

The lack of any reactions after LAS challenges in the workers suggests that the ability of SINOS to induce asthma is not directly related to its surface active properties. It has been suggested that such agents are capable of disrupting gastrointestinal epithelial surfaces ${ }^{10}$ and whereas we are unaware of any similar studies in the lungs, airway epithelial disruption is increasingly being recognised in association with asthma. ${ }^{11}$ Our results, however, are consistent with the widespread industrial experience with LAS during which few respiratory problems ${ }^{12}$ (and no occupational asthma) have been reported.

No symptoms, LARs, or changes in NSBR occurred in the control subjects after SINOS. This suggests that whatever the mechanism of action of SINOS, it is a specific one and accords with the latent period between the onset of occupational exposure and the development of symptoms. SINOS asthma therefore appears similar to other varieties of occupational asthma where immunological hypersensitivity is presumed. Immune reactivity to this chemical has not been shown (personal communication with manufacturer) and the mechanism of SINOS asthma remains undefined. Detergents formulated for domestic use are less likely to be respirable and this together with the specificity of SINOS asthma suggests that it is unlikely to pose any hazard to the consumer. Furthermore, improved industrial hygiene standards during manufacture should allow SINOS to be used safely in the occupational setting.

1 Hendrick DJ, Connolly MJ, Stenton SC, Bird AG, Wintert IS, Walters EH. Occupational asthma due to sodium is nonanoyl oxybenzene sulphonate, a newly developed detergent ingredient. Thorax 1988;43:501-2.

2 Davidsohn A, Milwidsky BM. Synthetic detergents. Londō G Goodwin, 1978.

3 Swisher RD. Surfactant biodegradation. New York: Març Dekker, 1987.

4 Connolly MJ, Avery AJ, Walters EH, Hendrick DJ. TBe relationship between bronchial responsiveness to methocholine and bronchial responsiveness to histamine in asthmatic subjects. Pulmonary Pharmacology 1988;1:53-8.

5 Stenton SC, Avery AJ, Walters EH, Hendrick DJ. Statistical aids in the identification of late asthmatic reactions (LARQR Thorax 1988;43:866P.

6 Hendrick DJ, Walters EH, Bird AG. Occupational asthma. Raffle PAB, Lee WR, McCallum RI, Murray R. Hunters diseases of occupations. London: Hodder and Stoughton, $198 \frac{q}{9}$

7 Venables KM, Newman Taylor AJ. Exposure-response relationships in tetrachlorophthalic anhydride asthma. $J$ Allergy Clin Immunol 1990;85:55-8.

8 Ihre E, Axelsson IGK, Zetterstrom $O$. Late asthmatic reactio and bronchial variability with low doses of allergen. Clin Allergy 1988;18:557-67.

9 Hargreave FE, Ramsdale EH, Pugsley SO. Occupational asthro without bronchial hyperresponsiveness. Am Rev Respir Dis 1984;130:513-5.

10 Kimura T, Imamura H, Hasegawa K, Yoshida A. Mechanisnor of toxicities of some detergents added to a diet and of te ameliorating effect of dietary fiber in the rat. $J$ Nutr Vitaminol 1982;28:483-9.

11 Laitinen LA, Heino M, Laitenen A, Kava T, Haahtela है Damage of the airway epithelium and bronchial reactivity patients with asthma. Am Rev Respir Dis 1985;131:599-606.

12 Oleru UG. Pulmonary function of exposed and control worke in a Nigerian nonsoapy detergent factory. Archiv Envirg Health 1984;39:101-6.

Accepted 28 November 1989 